\title{
Point-and-Click Pedagogy: Is it Effective for Teaching Information Technology?
}

\author{
Mark G. Angolia and Leslie R. Pagliari \\ East Carolina University, Greenville, NC, USA \\ angoliam@ecu.edu; pagliaril@ecu.edu \\ Abstract
}

This paper assesses the effectiveness of the adoption of curriculum content developed and supported by a global academic university-industry alliance sponsored by one of the world's largest information technology software providers. Academic alliances promote practical and futureoriented education while providing access to proprietary software and technology. Specifically, this paper addresses a lack of quantitative analysis to substantiate the perceived benefits of using information technology "point-and-click" instructional pedagogy to teach fundamental business processes and concepts. The analysis of over 800 test questions from 229 students allowed inferences regarding the utilization of self-directed "point-and-click" driven case studies employed to teach software applications of business processes needed for supply chain management. Correlation studies and analysis of variance investigated data collected from 10 individual course sections over a two-and-one-half-year period in a four-year public university. The data showed statistically significant positive correlations between the pedagogy and conceptual learning. Further, the research provided evidence that the methodology is equally effective for teaching information technology applications using either face-to-face or distance education delivery methods.

Keywords: Information technology, point-and-click, academic alliances, IT education, business process integration, pedagogy.

\section{Introduction}

Hawking and McCarthy (2004) conducted research summarizing studies discussing the implementation of academic alliances to benefit the student experience for information technology (IT) higher education. The primary instructional tools provided through these alliances rely upon highly detailed "point-and-click" $(\mathrm{P} \& \mathrm{C})$ instructions for students to navigate software applications. However, these studies typically investigated the benefits of information technology (IT) education utilizing student opinion surveys to assess the efficacy of the curriculum (Hawking \&

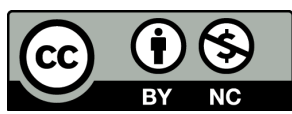

This article has been copyrighted by the Informing Science Institute on behalf of its authors. We license it to you under a Creative Commons AttributionNonCommercial 4.0 International License. When you copy and redistribute this paper in full or in part, you need to provide proper attribution to it to ensure that others can later locate this work (and to ensure that others do not accuse you of plagiarism). You may (and we encourage you to) adapt, remix, transform, and build upon the material for any non-commercial purposes. This license does not permit you to use this material for commercial purposes.
McCarthy, 2004; Rienzo \& Han, 2011). This paper provides quantitative analysis to support the benefit of using academic alliance curriculum to teach IT application software effectively and provide indepth understanding of the business processes involved. The research is based on Enterprise Resource Planning (ERP) education supported by the SAP University Alliance (SAP UA). The ERP curriculum supports a supply chain management degree program as the skills gaps related to information technology and the globalized marketplace take on increasing significance (Nepal \& Kumar, 2015). 
Rienzo and Han (2011) cited multiple references postulating that student self-assessment is appropriate as a research method, as no validated instrument exists to measure process knowledge of ERP systems. Research predominantly used assessments of pre-and-post activity questions to relate high-level activities to business processes. The conclusion was that self-assessment is an appropriate measurement, as the role of ERP exercises is to increase awareness of business processes' complexity and integration into an organization. Hepner and Dickson (2013) also presented a literature review of information system curricula within business programs, summarizing current research on the benefits ERP software integration. Their research found very little quantitative data on the efficacy of ERP integrated courses providing tangible benefits for students or universities. Taken together, these results confirmed the authors' review of literature that while student self-assessments show a positive relationship between business process comprehension and hands-on ERP skills work, there is a lack of empirical evidence of improvement of business process knowledge.

The design for this research takes a quantitative approach using correlation and analysis of variance (ANOVA) to establish if there is a positive association of demonstrated SAP skills against desired conceptual content education. Data were collected from 10 sections of a 2000 level Introduction to Enterprise Resource Planning course, from fall 2013 through spring 2016. SAP competency was assessed with exam questions and compared to a student's knowledge of final exam conceptual questions. A quantitative assessment of 229 students is discussed to confirm the positive relationship between self-directed point-and-click case study instructional pedagogy and the conceptual understanding gained.

The paper is organized to first provide background of ERP as a core application of IT and the business processes utilized for supply chain management (SCM). Additionally, academic alliances are defined along with their place within higher education by establishing benefits to academic institutions, faculty, and students. Next, the methodology for the study is defined starting with the Kolb Learning Cycle as the foundational theory for the application of the case study pedagogy presented herein. Methodology concludes with a statement of three focused research questions and data collection. Data analysis and results follow to establish the relationship between the application of hands-on IT activities and conceptual learning. Comparative analysis is also conducted to determine the impact of face-to-face (FTF) or distance education (DE). The paper concludes with a discussion of results detailing practical implications of utilizing point-and-click pedagogy and recommendations for start-up and participation in academic alliances.

\section{Background}

\section{Supply Chain Management and Enterprise Resource Planning}

SCM may be considered a network of autonomous, or semi-autonomous, business enterprises synergistically engaged in procurement, manufacturing, and distribution of product. ERP systems are designed to integrate the many business processes and databases needed to operate a given business (an enterprise). Therefore, ERP is a clear path for operational, managerial, and strategic systems thinking (Su \& Yang, 2010). Fundamentally, ERP systems enable an enterprise, and by extension a supply chain, by inputting instance level information, accessing relevant process data, and utilizing multiple business processes for decision making. Recent research has shown an increase of importance on the integration of planning, control, and execution of materials, resources and operations upon business performance, and hence, the relative importance of ERP as a critical system (Su \& Yang, 2010). In general, enterprise systems education equips students with a process-centric background which emulates today's corporate climate (Antonucci, Corbitt, Stewart, \& Harris, 2004). 
As ERP is a highly automated IT practice, it prospers from adoption of best practices. Dhillon (2005) hypothesized that the real benefits of ERP reside in the changes to organizational activities which can be engineered, and then implemented by an IT function. A research model by Su and Yang (2010) utilized five ERP constructs: operational, managerial, strategic, IT infrastructure, organizational benefits, and three SCM competencies: operations, planning, and control. Their work concluded that ERP tenants of operational, managerial, and strategic processes are significant predictors of SCM success. Additionally, they supported the majority of research that ERP systems can become the "backbone of company operations".

\section{Academic Alliances}

Typically, academia cannot afford licenses and/or maintenance fees for cutting edge IT that result in a hodgepodge of applications being taught within and across departments (Corbitt \&

Mensching, 2000). Thus, selection of commercial software is usually based on hardware/software affordability and availability rather than an extensive selection process intended to find an optimal application or provider to be integrated into the curriculum in a coordinated manner. An academic alliance is a coalition of member universities and a commercial enterprise, acting as a catalyst and sponsor to bring together academia and technology. The goal of academic alliances is to form a symbiotic relationship between faculty, commercial software providers, and students. The business entity is generally a software provider with products and services typically cost prohibitive to universities, but with global impact and wide commercial use. With an academic alliance, the provided software becomes a common denominator for all parties as commercial enterprises attempt to bridge a pedagogical gap between academic/theoretical training and "skills" training.

This is not a completely altruistic endeavor by the software provider, as the commercial intent is to create a generation of future analysts, technologists, and managers conversant with their products, essentially making the academic alliance an investment. Through an academic alliance, faculty working on a common platform gain access to a worldwide network of colleagues engaged in common academic pursuits, peer reviewed curriculum content, academic conferences for idea sharing, and access to state-of-the-art commercial software. The sponsor provides products along with an infrastructure for a central repository of exercises, case studies, simulations, and other pedagogical content to create a resource for faculty to incorporate material.

From the university standpoint, academic alliances are a cost effective and efficient way to bridge the gap between public university missions and demands created by the financial realities of decreasing state support. Economic impact and student employment are becoming the new metrics as public universities are increasingly challenged to demonstrate quantifiable economic benefits. Words like "skills" are starting to enter individual university missions, supplanting more esoteric phrases like discover, create, transmit, and apply knowledge. This provides a degree of anecdotal evidence allowing for skills related training to complement traditional theoretical/conceptual higher education pedagogy. Additionally, the readily available curriculum material supported by the alliance's infrastructure helps universities advance through the early stages of the ERP Maturity Model for Higher Education presented by Antonucci, Corbitt, Stewart, and Harris (2004).

This paper is based on the SAP UA which includes 2,650 universities worldwide in over 90 countries and provides access to the entire SAP license portfolio free of charge, including curricula, webinars, events, learning platforms, and certifications/awards (SAP University Alliances 2015). The stated goal of the SAP UA is to prepare students and gain a presence within college curricula while simultaneously developing "job ready" graduates with SAP skills and IT knowledge (Corbitt \& Mensching, 2000). However, SAP is not the only software provider sponsoring ERP related academic alliances. Another widely used alliance is supported by Microsoft which hosts the Microsoft Dynamics Academic Alliance (DynAA) to over 1,400 educational institutions (Microsoft dynamics academic alliance CRM \& ERP.2015). Microsoft provides a full installation of 
Dynamics in order to provide leadership, relevance, curricula, academic research, and innovation. Membership in the DynAA provides software licenses and product upgrades, documentation, knowledge bases, e-learning, training material, curriculum and related materials, and certifications. The goal of both of these academic alliances is to engage with partner companies and universities to enhance students' job opportunities, as well as foster technology and student success. Typical learning modules from both providers are shown in Table 1.

Table 1. ERP modules and related content from academic alliances

\begin{tabular}{|c|c|}
\hline Business Process Management & Production Planning \\
\hline - Sales \& Distribution & - Materials Masters \\
\hline - $\quad$ Materials Management & - Bill of Materials \\
\hline - $\quad$ Production Planning & - Routings \\
\hline - $\quad$ Financial Accounting & - $\quad$ Forecasting \\
\hline - Management Accounting & - $\quad$ Sales \& Operating Planning \\
\hline - Human Capital Management & - Master Schedule \\
\hline - Warehouse Management & - Materials Requirement Planning \\
\hline - $\quad$ Project Systems & - $\quad$ Purchasing \\
\hline - $\quad$ Asset Management & - $\quad$ Financial Accounting \\
\hline - $\quad$ Customer Service & \\
\hline
\end{tabular}

\section{Student Benefits}

Research by Fedorowicz, Gelinas, Usoff, and Hachey (2004) concluded that employers expect new hires to "understand how companies function" and require "knowledge of basic business processes and technology". They also concluded that an integrated enterprise software curriculum "exposes students to the elaborate interdependencies" of internal business systems, which may be considered a critical concept to operational initiatives to be undertaken in industry. Another 2004 study stated that students have difficulty dealing with real-world situations that often require a multidisciplinary understanding and approach to resolve (Cannon, Klein, Koste, \& Magal, 2004). Students had difficulty in seeing the linkage of the various business processes and functions needed to form an integrated enterprise system information system (Huynh \& Chu, 2011). In 2014, research by Ma, Teng, Du, and Zhang (2014) determined that some enterprise managers felt that higher education ignores hands-on skills training and that there was too much "isolation" between teaching and practice.

The common thread between the 2004 and 2014 research is that over the past decade there has been continued concern that newly graduated millennials need an appreciation for business processes, workflow, and inter-organizational dependencies to manage complex systems, such as supply chains. The ramification is that graduates are out of touch with business needs and unfamiliar with popular commercial software and fundamental IT applications. Traditional pedagogy for teaching procurement, manufacturing, and distribution as distinctive functions was not deemed effective. Untener, Mott, and Jones (2015) posited that graduates are best positioned to enter industry "through pedagogy and courses that provide foundational principles and experiential/active learning to apply those principles to realistic problems". The point-and-click student exercises provided through Academic Alliances have become the primary tool to provide IT experiential learning to meet this need. The student benefits from the academic alliance as they are provided with marketable skills to enhance their job search. These skills complement their theoretical education, critical thinking, and other top tier attributes within Bloom's hierarchy (Armstrong, 2016). The next section discusses how the Kolb Learning Cycle is an effective approach to utilizing pedagogy available through an academic alliance. 


\section{Method}

\section{Educational Theory}

In defining an appropriate course framework, key considerations included: (1) two different delivery systems, referred to as "sections" in the data analysis; (2) two likely student demographics; and (3) the need for "expert-user" interaction for software problem resolution. The course is delivered as FTF and DE, for both the traditional 18-22 year-old demographic and for adult learners. There are some adult learners in the FTF sections, but most are primarily DE. For adult learners, the principles and theories of andragogy were a consideration. While pedagogy is generally considered as "teacher delivered and managed" instruction, andragogy is focused on adult learners and is primarily "learner-centered/directed." Online education research recommends andragogy for self-directed learners that need flexibility to navigate a structured online class (Bailey \& Card, 2009).

Due to the DE delivery and nature of the point-and-click pedagogy employed, andragogy was considered for its focus on independent/self-directed learning attributes. However, ERP systems lack an intuitive nature for most students, and student input errors typically require instructor intervention to recover. Additionally, a critical aspect of the course structure is keeping the same pace/progress for all students in order to discuss conceptual issues as the SAP transactions are executed. Thus, teaching ERP software through self-directed, un-supervised point-and-click instruction is not recommended when the focus is on both technical IT learning and conceptual knowledge.

A review of literature by Althouse and Hedges (2015) determined that Generation X, Y, and Z students will adapt to traditional textbook learning, but gravitate to activity-based learning that provides theory and some type of "instant gratification". In using the SAP UA exercises and case studies, the point-and-click activities become the instant gratification, to complement traditional lecture and textbook content. Information systems' instructors should not assume students are familiar with the technology application used within their course (Drake, 2012). Most ERP systems are not very intuitive, especially to students without any real-world experience. To meet these challenges for an undergraduate student demographic which generally has little or no hands-on experience, an active learning approach based is proposed.

The Kolb Experiential Learning Cycle was selected as it proposes that the most effective instruction involves repetitive teaching around a four quadrant cycle that includes: (1) abstract conceptualization; (2) active experimentation; (3) concrete experience; and (4) reflective observation. An important contributing success factor for the Kolb cycle is that it does not require assessing individual student learning style preferences, since teaching around the cycle ensures all are addressed (Felder \& Brent, 2005). Additionally, Untener et al. (2015) recommend a variety of experiences to match different learning styles in order to achieve varied and higher levels of Bloom's taxonomy.

The Kolb Cycle establishes the instructor's role of "motivator" and "expert" for learner types that are most suited for lecture and written assessments (Felder \& Brent, 2005), which are typically addressed with textbook content. Instructors create a foundational base of theory and technical tools needed for project initiation, planning, execution, monitoring, and closure. The goal is reflective observation and abstract conceptualization by the students, as preparation for active experimentation and concrete experience. Experiential learning exercises are provided by active experimentation and exploration, while concrete experience is provided via practice opportunities. The use of application-oriented software, initially supported with a theoretical underpinning, facilitates an active learning component. Integrating commercial software attained through aca- 
demic alliances to create activities which alternate between theory and experiential learning will tend to propagate the Kolb cycle and enhance learning.

Kolb's experiential learning framework, learning styles, and learning cycle was adapted to model how experience can be translated into conceptual competencies (Botelho, Marietto, Ferreira, \& Pimentel, 2015). This model has been further adapted by the authors as shown in Figure 1 to establish a framework to integrate point-and-click case studies and conceptual knowledge. The proposed entry point is abstract conceptualization, where textbook and lecture present business processes. Active experimentation begins with the SAP exercises provided by the academic alliance and paper forms processed in parallel. Concrete experience is provided through students executing $\mathrm{P} \& \mathrm{C}$ driven case studies and solving problems initiated by their input errors. Finally, reflective observation is the post case study discussion led by the instructor to relate the SAP transactions with business processes and concepts.

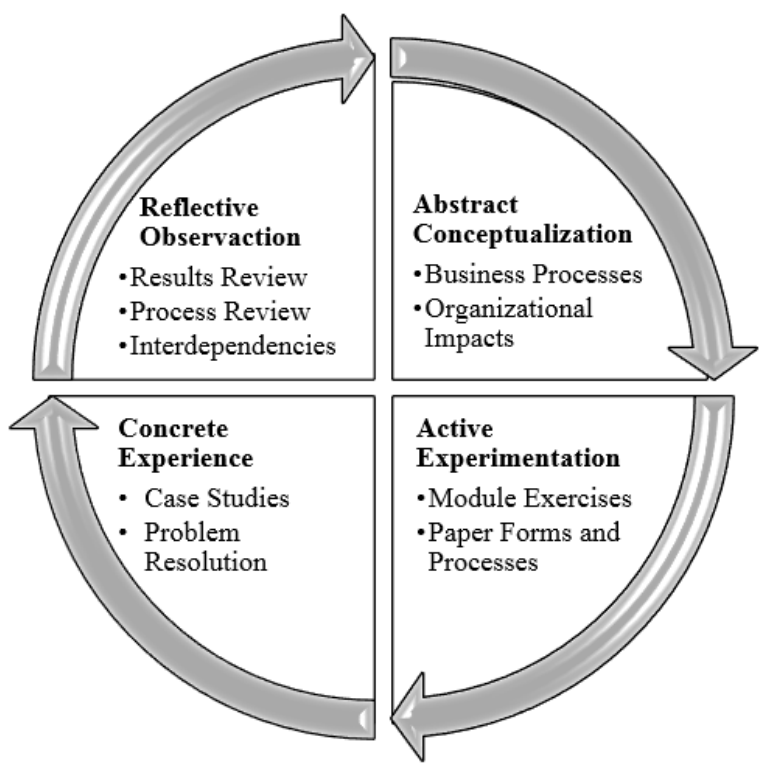

Figure 1. Kolb's Experiential Learning Cycle (adapted from Kolb, 1984)

The approach taken with this pedagogy is suitable for both FTF and DE students. The addition of active learning and academic alliances is not meant to replace traditional textbook and lecture pedagogy, but rather to enhance student outcomes through inclusion of skills to complement theoretical concepts. A prior command of principles and theory must be developed to facilitate the transfer of knowledge from the experiential learning gained through utilization of commercial software (Untener et al., 2015). The textbook becomes a reference for students to seek explanations to understand the "what" and "how" of the software applications. The next section describes the multiple modules and case studies used to provide the repetitive experience recommended for efficacy of the Kolb Cycle.

\section{Pedagogy}

Utilized for this study is a sophomore level required course, Introduction to ERP Systems, delivered to both FTF and DE students. The pedagogy included fundamental SAP ERP software modules based on an SAP UA provided data set for a fictional enterprise as a nucleus company within a supply chain. Each course section followed a similar learning process using textbook readings, lectures, SAP ERP exercises, discussion questions, and SAP case studies. The exercises and case studies are both P\&C instructions to guide students for the SAP transactional work. 
Table 2 shows the modules, content, and time estimate for the work. All modules and SAP work are independent of each other, but related to the same enterprise client. As any commercial software will be new to students, a navigation module is first required to provide a rudimentary understanding of the user interface and methodology. For each subsequent learning module, students first read textbook material accompanied by lecture and discussion. Next, SAP P\&C exercises introduce high level fundamental business processes. The preliminary exercise provides an abbreviated experience of the business processes to be modeled in greater depth by the subsequent case study. The SAP case study dives deeper into transactions, business processes, and conceptual detail. Students operate the company using a live, real-time SAP ERP environment.

Table 2. SAP modules utilizing point-and-click case study content

\begin{tabular}{|l|l|c|}
\hline \multicolumn{1}{|c|}{ SAP Module } & \multicolumn{1}{c|}{ Business Processes } & Weeks \\
\hline Sales and Distribution (SD) & sales quote to cash cycle & 3 \\
\hline Materials Management (MM) & procurement of trading goods & 3 \\
\hline Production Planning (PP) & production planning of finished goods & 3 \\
\hline $\begin{array}{l}\text { Warehouse Management Systems } \\
\text { (WMS) }\end{array}$ & $\begin{array}{l}\text { receiving, putaway, warehouse addressing, } \\
\text { order picking, shipping }\end{array}$ & 2 \\
\hline
\end{tabular}

The case studies within this pedagogy are of a single SAP client that manufactures and distributes bicycles. Print-outs of step-by-step P\&C instructions are used to complete SAP transactions for each step of the business processes demonstrated by the case studies. Students are required to role play several different functional positions in the organization to gain understanding of the interaction and impact of the ERP system across an enterprise. Using the SD module from Table 2 as an example, students will operate a live SAP ERP system to complete all business process involved in the sales quote to cash receipt cycle. Students begin the case study in the role of an "inside salesperson" creating a customer master record for a new prospective customer. This prospect has sent in an inquiry/request for quote (RFQ) to procure bicycles from the company's distribution center (DC). The student records information from the RFQ, issues a quote as a response, and ultimately enters a purchase order from the customer. The role of "inside salesperson" is completed with the creation of a sales order to initiate the fulfillment processes from the DC. Figure 2 shows a sample SAP instruction and screen capture illustration for critical required data entries. Purposeful text boxes, also shown in Figure 2, are used as needed for higher level explanation at select points to provide detail - a "why" and "what" supplemental explanation. Continuing with the case study, the student next assumes the role of "warehouse associate", creating and managing all the business processes to pick the material from inventory, ship bicycles to the customer, and generate an invoice to request payment. The case study instructions conclude with the student assuming the role of "accounts receivable clerk" to record the receipt of funds from the customer into the company's general ledger.

A critical success factor tied to $\mathrm{P} \& \mathrm{C}$ instruction is practice, feedback, and repetition (Stanton, Porter, \& Stroud, 2001). Practice comes from the initial exercise that precedes the more in-depth SAP module case study. Repetition is from instruction for the four different SAP modules. To facilitate feedback, a key supplement to the P\&C case studies is a complementary set of discussion questions regarding core competencies. Focused conceptual questions are posed, which relate specific $\mathrm{P} \& \mathrm{C}$ instructional steps to the targeted business processes involved. These are intended to establish a direct link between the SAP transactions and the supply chain management concepts involved. After completion of SAP work, a module exam consisting of SCM content and SAP proficiency questions is conducted. The exercise-case study sequence, in conjunction with proceeding through the four modules, also provides the degree of repetition needed for the Kolb Cycle. 


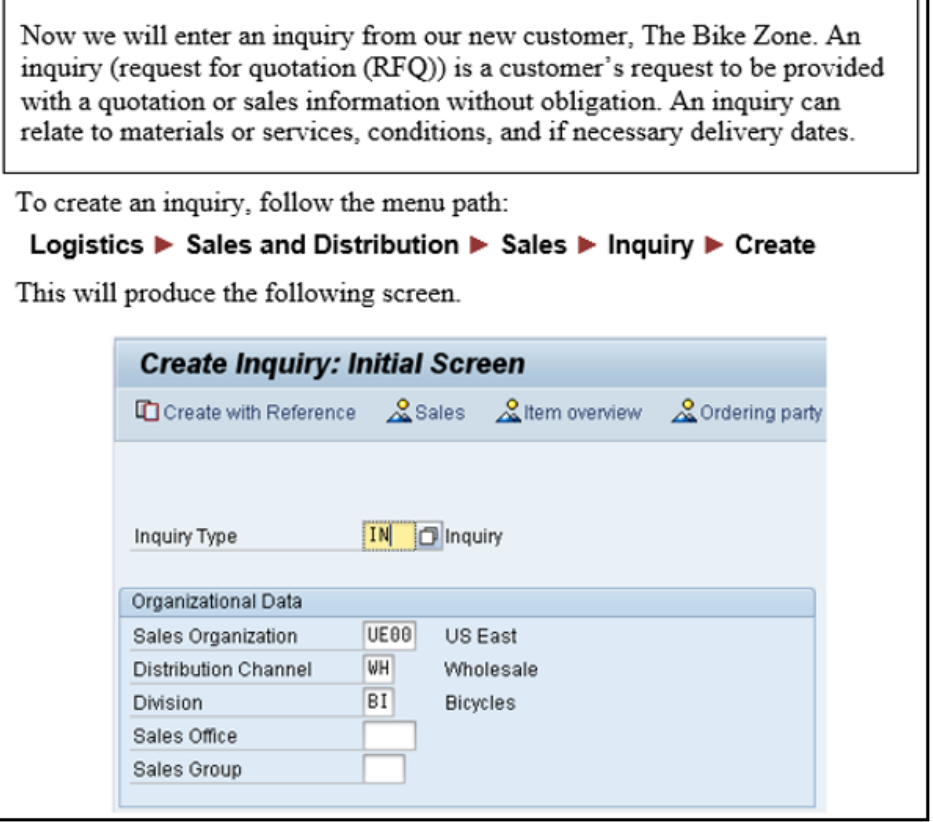

Figure 2. Screen capture of point-and-click instructions

In semesters the course was taught concurrently to FTF and DE students, the same content was made available to both delivery methods through the Blackboard course management system. Identical assessments and rubrics were used as well. Distance students were provided instructor led synchronous video sessions and asynchronous discussion forums to compensate for the interaction gained by the FTF students. Both delivery methods had instructor-narrated video tutorials for the solution of all SAP specific point-and-click activities. The next section defines three research questions used to guide data analysis of the efficacy of the P\&C pedagogical approach.

\section{Research Questions}

To assess the effectiveness of the repetitive SAP point-and-click active learning assignments based on the Kolb Cycle, all of the module and final exams included a combination of "hands-on" SAP proficiency questions and supply chain management business process related content questions. For the exam SAP questions, students were required to navigate the software to look up answers to "open response" questions. Business process (BP) content questions were a variety of multiple choice, multiple answer, matching, fill in the blank, true/false, and open response. Within each semester, FTF and DE students utilized the same SAP active learning assignments and questions, although there were differences semester to semester due to continual improvement actions by the instructor. The only pedagogical difference between the FTF and DE sections was completion of a pre-and-post business process simulations for the FTF sections. The instructor's contextual theory is that DE students are generally adult learners with some level of business experience.

\section{Research Question 1}

Does the inclusion of SAP UA business process management point-and-click case studies have a positive effect on learning business processes related to supply chain management?

Question 1 (Q1) used correlation to assess if there was any relationship between SAP competency, gained through the completion of the SAP UA case studies, and the cognition of business process knowledge for fundamental supply chain operations. First, the entire data set consisting of the five DE and five FTF sections was analyzed as a total data set. Next, data were grouped by 
the five DE and five FTF sections to determine the impact of delivery. Finally, individual course sections were analyzed. Individual exam questions were used to create an Average of SAP question scores (Ave SAP) from the module exams and the final exam. Business process knowledge and conceptual learning were derived based on the final exam questions relating to supply chain concepts (BP Final). The SAP Ave was correlated against the BP Final as follows:

1. All 10 sections (combined five DE plus five FTF)

2. Five sections of combined DE only data

3. Five sections of combined FTF only data

4. Each of the 10 class sections evaluated individually

\section{Research Question 2}

Is the effectiveness of the SAP UA business process management (BPM) point-and-click case studies the same for face-to-face and distance education students?

Question 2 utilized the entire data set, grouped by DE and FTF delivery. Separate comparison of means for Ave SAP and BP Final scores was undertaken using ANOVA. The data was first tested for ANOVA assumption validity to establish methodology credibility, then the DE sections were compared to FTF sections for the following:

1. SAP Competency

2. Business Process Knowledge

\section{Data Collection}

The student population for the study was comprised of 229 undergraduates from 10 total sections, five DE comprised of 124 students and five FTF delivery sections with 105 total students. The studied sections began with the fall 2013 semester and ended with the spring 2016 semester. The 10 sections each included a "Sales and Distribution" module exam, a "Materials Management" module exam, and a final exam. Data were organized by student, year, semester, and delivery method (FTF or DE). The challenge in analyzing the data stemmed from variation of point values and number of SAP and content questions in each exam. Since module and final exam grades could not be utilized due to mixed question types and point values and curves, individual exam questions were categorized by type, either SAP competency related or BP concepts. In all, 840 exam questions were categorized as either related to assessing SAP competency or a conceptual knowledge of business process as related to supply chain management.

SAP competency was evaluated by analyzing individual test questions from two separate module exams and the final exam from each course section. SAP questions required students to have a working knowledge of the software navigation and functionality, as well as being able to interpret various data screens. These were identified in order to separate the P\&C instructional effectiveness from the balance of the questions testing the student's conceptual knowledge. There were 286 individual questions over the 10 class sections in the study. The business process knowledge was evaluated by analyzing individual test questions from the final exam only, and does not include any of the SAP specific questions. In total, there were 554 individual content related questions over the 10 class sections in the study.

Pivot tables were used to sum up the total possible question points for the SAP questions and a column created to determine the percentage based on the total possible point value. The process is repeated for the conceptual questions in the final exam only. The raw data were summarized by individual courses for all semesters and exported into SAS JMP 12 pro. Students who dropped the course were purged from the data set since the correlation statistics and ANOVA were based on the final exam and their data points on earlier modules would have biased the results. 
All students in the study used the same SAP case studies created by the SAP UA and had the same access to resources, based on the delivery method. Each individual semester in the study, students received the same exam questions, delivered through the same course management system (Blackboard), with common time limits. Exams were "open book" for all students to preclude any bias for the un-proctored exams given to the distance students. The analysis and results section follows with detailed analytics and discussion on each research question.

\section{Analysis and Results}

\section{Research Question 1}

\section{Q1.1: Correlation of Ave SAP to BP Final exam scores, all data}

Figures $3 \mathrm{a}$ and $3 \mathrm{~b}$ show descriptive statistics for each variable. The center box of the histogram with box plot shows the interquartile range (IQR) representing the middle $50 \%$ of all values, with the median as the vertical line centered within. The diamond represents the mean value at the center and the upper and lower $95 \%$ confidence bands at the diamond edges. The upper and lower fences are located 1.5 IQRs from the $25 \%$ and $75 \%$ quartile lines. The horizontal bracket represents the smallest grouping of points representing $50 \%$ of the data. The detailed histograms in the appendix show outliers; however, all analysis includes these points as there are no objective reasons to exclude them.

Table 3 provides the detailed values for all student data, separated by the study variables of average SAP question scores and the average of the business process (BP) questions scores. Given the close proximity of the mean and median for the individual variables, along with skewness $<0.50$ and the extremely small kurtosis values, the data are judged to be normal irrespective of the outliers present. As an additional observation, the mean and median scores are very nearly centered with a "C" average. The authors feel this provides a degree of "fairness" to the testing utilized within the study population.

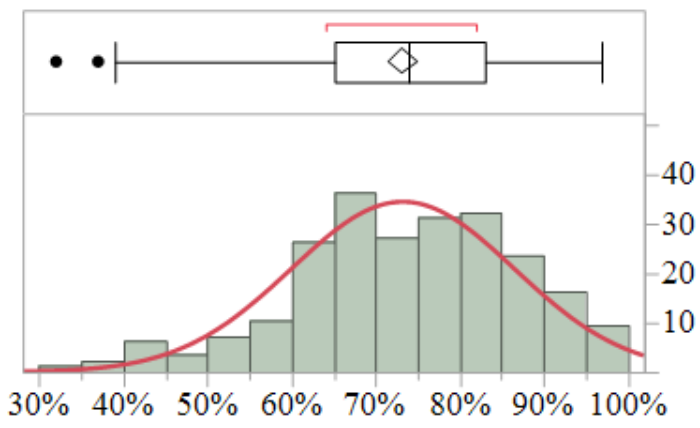

Figure 3a. Average SAP, all sections

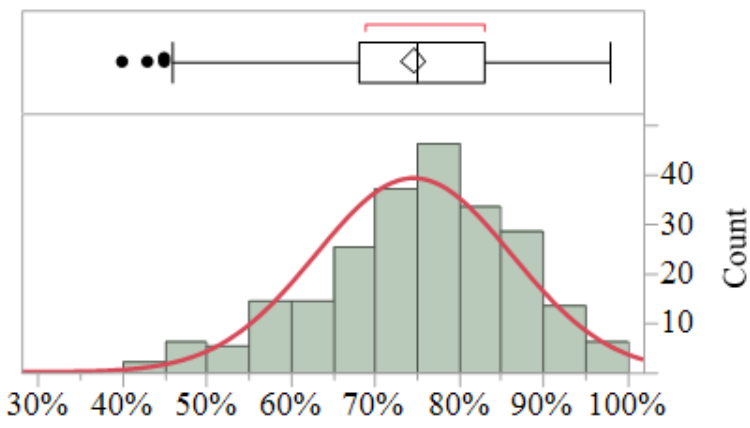

Figure 3b. BP score average, all sections

Table 3. Descriptive statistics, all data by study variables

\begin{tabular}{|c|c|c|}
\hline Statistic & Average SAP & BP Score \\
\hline $\mathrm{N}$ & 229 & 229 \\
\hline Mean & 0.7328 & 0.7469 \\
\hline Median & 0.7400 & 0.7500 \\
\hline Std. Deviation & 0.1328 & 0.1166 \\
\hline Skewness & -0.4920 & -0.4980 \\
\hline Kurtosis & -0.0010 & 0.0341 \\
\hline
\end{tabular}


Figure 4 graphically represents a scatter plot of the entire data set consisting of all of the individual data average SAP calculations (Ave SAP) and the percent correct of final exam business process related questions (BP Final). In addition to the scatter plot, a linear regression best fit line is shown, along with a 95\% density ellipse for individual data points. The Pearson $r$ correlation coefficient was 0.531 between the average score on SAP related questions when compared to the average score on general supply chain management related business process questions given on the final exam. Table 4 shows Prob $>|t|$ for the slope of the line shown by the Ave SAP parameter estimate value is less than $\alpha=0.05$; thus the positive correlation is considered statistically significant.

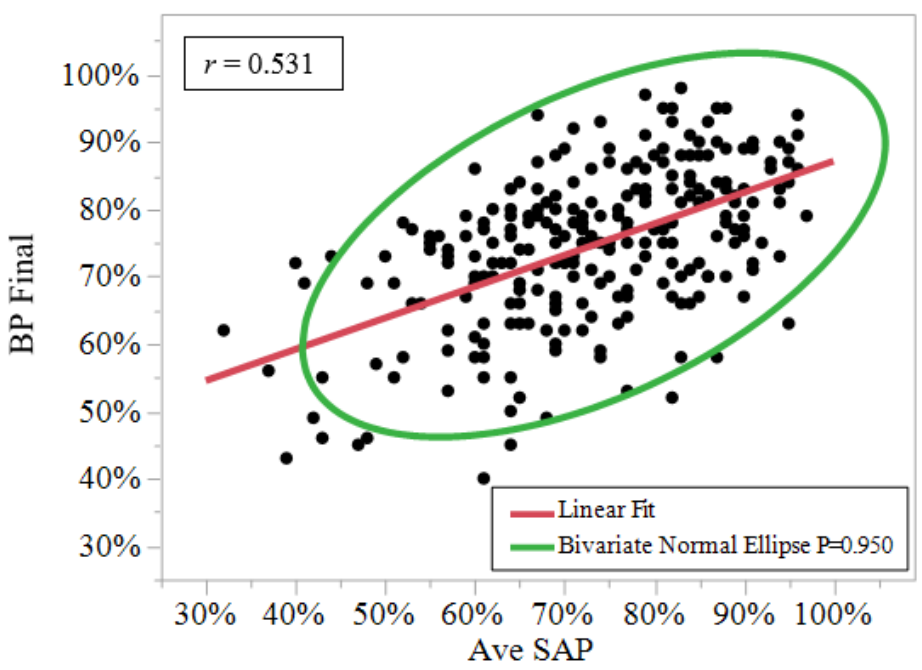

Figure 4. BP final by Ave SAP (all)

Table 4. Parameter Estimates, Ave SAP by BP Final, all data, $\mathbf{n}=\mathbf{2 2 9}$

\begin{tabular}{|l|c|c|c|c|}
\hline Term & Estimate & Std Error & $t$ Ratio & Prob $>|t|$ \\
\hline Intercept & 0.4054 & 0.0367 & 11.02 & $<.0001^{*}$ \\
\hline Ave SAP & 0.4660 & 0.0493 & 9.44 & $<.0001^{*}$ \\
\hline
\end{tabular}

* significant at $\alpha=0.05$

\section{Q1.2: Correlation of Ave SAP to BP Final, DE combined data}

Table 5 shows the descriptive statistics for the correlation factors for the five combined DE sections, and for Q1.3, the five combined FTF sections are also contained within. Both delivery methods represent normally distributed data given the close proximity of the mean and median, along with skewness $<1.0$ and the extremely small kurtosis values. The detailed histograms in the appendix show outliers, however, all analysis includes these points as there are no objective reasons to exclude them.

Table 5. Descriptive statistics by delivery method

\begin{tabular}{|l|r|r|r|r|}
\hline \multirow{2}{*}{ Statistic } & \multicolumn{2}{|c|}{ Distance Delivery $(D E)$} & \multicolumn{2}{r|}{ Face-to-Face Delivery (FTF) } \\
\cline { 2 - 5 } & Average SAP & BP Score & Average SAP & BP Score \\
\hline $\mathrm{N}$ & 124 & 124 & 105 & 105 \\
\hline Mean & 0.7266 & 0.7706 & 0.7400 & 0.7189 \\
\hline Median & 0.7300 & 0.7900 & 0.7400 & 0.7100 \\
\hline Std. Deviation & 0.1481 & 0.1088 & 0.1123 & 0.1197 \\
\hline Skewness & -0.4163 & -0.9534 & -0.5238 & -0.0416 \\
\hline Kurtosis & -0.4333 & 0.8960 & 0.6293 & -0.0055 \\
\hline
\end{tabular}


Figure 5 graphically represents a scatter plot of the combined data for the five DE sections, consisting of 124 individual data average SAP calculations (Ave SAP) and the percent correct of final exam business process related questions (BP Final). In addition to the scatter plot, a linear regression best fit line is shown, along with a $95 \%$ density ellipse for individual data points. The Pearson $r$ correlation coefficient was 0.615 between the average score on SAP related questions when compared to the average score on general supply chain management related business process questions given on the final exam. Table 6 shows the Prob $>|t|$ statistic for the slope of the line shown by the Ave SAP parameter estimate value is less than $\alpha=0.05$, the positive correlation is considered statistically significant.

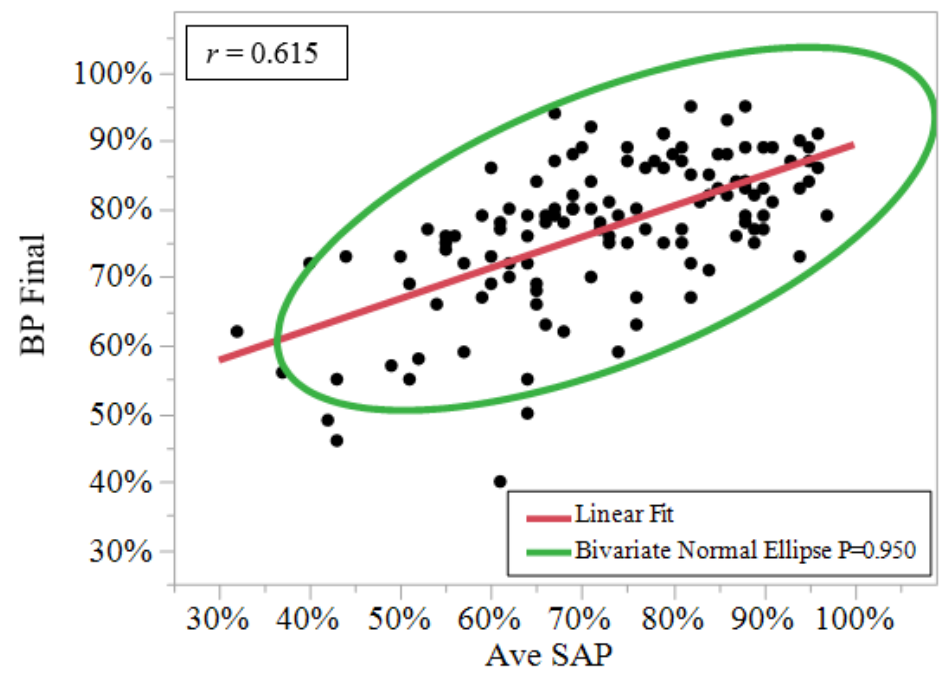

Figure 5. Fit of BP Final by Ave SAP (DE)

Table 6. Parameter estimates, Ave SAP by BP Final, all DE sections, $\mathbf{n}=124$

\begin{tabular}{|l|c|c|c|c|}
\hline Term & Estimate & Std Error & t Ratio & Prob $>|t|$ \\
\hline Intercept & 0.4423 & 0.0389 & 11.37 & $<.0001^{*}$ \\
\hline Ave SAP & 0.4517 & 0.0524 & 8.61 & $<.0001^{*}$ \\
\hline
\end{tabular}

* significant at $\alpha=0.05$

\section{Q1.3: Correlation of Ave SAP to BP Final, FTF, combined data}

Table 5 shows the descriptive statistics for the correlation factors for the five combined FTF sections. Figure 6 graphically represents a scatter plot of the combined data for the five FTF sections, consisting of 105 individual data average SAP calculations (Ave SAP) and the percent correct of final exam business process related questions (BP Final). In addition to the scatter plot, a linear regression best fit line is shown, along with a $95 \%$ density ellipse for individual data points. The Pearson $r$ correlation coefficient is 0.496 . Table 7 shows the Prob $>|t|$ statistic for the slope of the line shown by the Ave SAP parameter estimate value is less than $\alpha=0.05$, the correlation is considered as a weak positive, but statistically significant. 


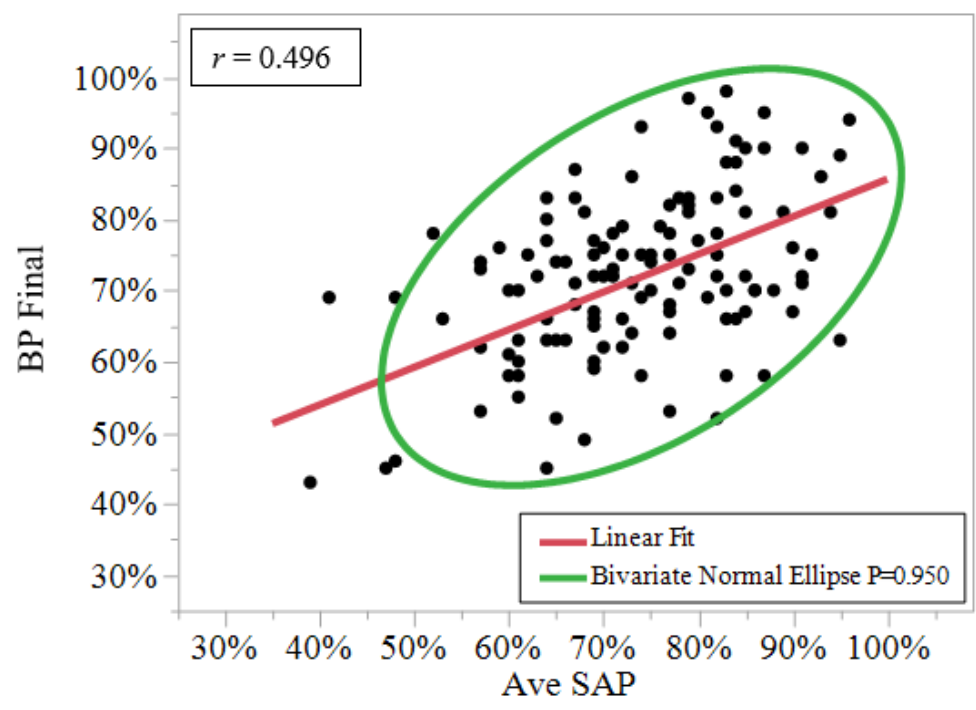

Figure 6. Fit of BP Final by Ave SAP (FTF)

Table 7. Parameter Estimates, Ave SAP by BP Final, All DE Sections, $\mathbf{n}=124$

\begin{tabular}{|l|l|c|c|c|c|}
\hline \multicolumn{1}{|c|}{ Term } & Estimate & Std Error & $t$ Ratio & Prob $>|t|$ \\
\hline Intercept & & 0.3274 & 0.0682 & 4.80 & $<.0001^{*}$ \\
\hline Ave SAP & & 0.5289 & 0.0911 & 5.80 & $<.0001^{*}$ \\
\hline
\end{tabular}

* significant at $\alpha=0.05$

\section{Q1.4: Correlation of Ave SAP to BP Final, all 10 sections individually.}

Following a similar procedure, scatter plots, regression lines, and density ellipses were plotted and analyzed for individual classes. Likewise, a correlation analysis was conducted for each individual class section to measure the degree of association between the SAP question average score and the business process question scores from the individual student final exams. Table 8 summarizes the results which show a statistically significant positive correlation between percentage of SAP proficiency questions and business concepts content questions from the final exam for each individual class section. The results for research question 1.3, showing correlation by delivery method, are also listed in Table 8 for convenience and comparison.

Table 8. Pearson Coefficients by Class Section: SAP Proficiency v. BPM Content

\begin{tabular}{|c|c|c|c|c|c|}
\hline \multicolumn{2}{|c|}{ Course Section } & \multicolumn{2}{c|}{ FTF Sections } & \multicolumn{2}{c|}{ DE Sections } \\
\hline Year & Semester & Students & Pearson $r$ & Students & Pearson $r$ \\
\hline All & All & 105 & $0.496^{*}$ & 124 & $0.615^{*}$ \\
\hline \multirow{3}{*}{2013} & & & & & \\
\hline \multirow{3}{*}{2014} & Fall & 19 & $0.611^{*}$ & & \\
\cline { 2 - 6 } & Spring & 17 & $0.532^{*}$ & 28 & $0.514^{*}$ \\
\cline { 2 - 6 } & Summer & & & 26 & $0.505^{*}$ \\
\hline \multirow{3}{*}{2015} & Fall & 17 & $0.673^{*}$ & & \\
\cline { 2 - 6 } & Spring & 23 & $0.674^{*}$ & 23 & $0.615^{*}$ \\
\cline { 2 - 6 } & Summer & & & 21 & $0.648^{*}$ \\
\hline 2016 & Fall & 29 & $0.665^{*}$ & & $0.653^{*}$ \\
\hline
\end{tabular}

* significant at $\alpha=0.05$ 


\section{Research Question 2}

Research question 2 investigated the entire data set to determine if the course pedagogy created equal learning outcomes for the DE and FTF students for both SAP competency and Business Process knowledge. To accomplish this, separate comparison of means for Average SAP and final exam business process scores was undertaken using ANOVA. However, prior to the application of ANOVA, three assumptions first had to be confirmed: (1) all observations are independent; (2) individual error terms are normally distributed; and (3) variance of individual errors are equal across treatment groups (DE and FTF sections).

For the first assumption, independence of observations, this is a logical rather than mathematical test, and in this case it is clear that each student and all exams are independent. The appendix contains the error terms (residuals) plot and corresponding histogram, along with detailed data for the variance of the individual errors for the second assumption. For the second assumption, the residuals analysis normal quantile plot shows all points are within the $95 \%$ confidence interval and are acceptable to assume the normality assumption is satisfied. However, for the third assumption, Levene's test demonstrated a $p$-value $=0.0007$ which is less than a critical value of $\alpha=0.05$. This resulted in rejecting the null hypothesis that there is no difference in variances for the different treatments, DE and FTF delivery. However, since the sample sizes are rather large and nearly equal, 124 and 105, the violation of the equal variance requirement will have minimal impact on the results. Additionally, as two of the three assumptions were met and ANOVA is relatively robust to the normality assumption if the residuals are "generally unimodal and symmetric," ANOVA results may be accepted (Carver, 2010).

\section{Q2.1 $\mathrm{H}_{\mathrm{o}}$ : There is no difference between the DE and FTF sections for mean Ave SAP scores.}

The ANOVA results graphically shown in Figure 7 visually demonstrate that there is significant overlap in the means for Ave SAP scores. The diamonds in each section represent the mean with the vertices representing the upper and lower $95 \%$ confidence bands. It is also apparent the box plots overlap as the FTF 50\% quartile is contained within the DE graph. As shown in Table 9, the Prob $>$ F statistic of 0.4483 is greater than $\alpha=0.05$, indicating we cannot reject the null hypothesis that there is no difference in the means.

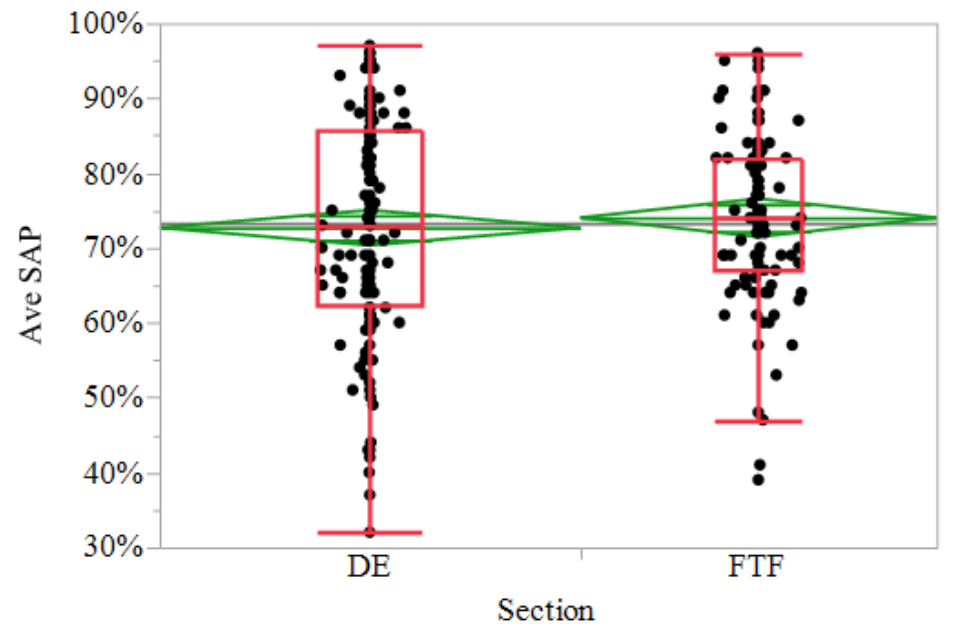

Figure 7. Analysis of Ave SAP by section (delivery method) 
Table 9. Analysis of variance, mean Ave SAP scores by delivery method

\begin{tabular}{|l|c|c|c|c|c|}
\hline Source & DF & Sum of Squares & Mean Square & F Ratio & Prob $>$ F \\
\hline Section & 1 & 0.0102 & 0.0102 & 0.5770 & 0.4483 \\
\hline Error & 227 & 4.0084 & 0.0177 & & \\
\hline C. Total & 228 & 4.0186 & & & \\
\hline
\end{tabular}

\section{Q2.2 $\mathrm{H}_{\mathrm{o}}$ : There is no difference between the DE and FTF sections for mean BP Final.}

The graphical results for the business process final exam scores are shown in the appendix. This graph exhibits a very similar overlap as shown in Figure 7, with mean scores of approximately $76 \%$ for DE and $73 \%$ for FTF, with overlapping confidence intervals. The ANOVA results are shown in Table 10. The Prob $>$ F statistic is 0.2417 , which is also greater than $\alpha=0.05$, indicating we cannot reject the null hypothesis that there is no difference in the means for the final exam scores for business process related question results between the DE and FTF delivery methods.

Table 10. Analysis of variance, BP Final scores by delivery method

\begin{tabular}{|l|c|c|c|c|c|}
\hline Source & DF & Sum of Squares & Mean Square & F Ratio & Prob $>F$ \\
\hline Section & 1 & 0.0444 & 0.0444 & 1.3776 & 0.2417 \\
\hline Error & 227 & 7.3242 & 0.0323 & & \\
\hline C. Total & 228 & 7.3687 & & & \\
\hline
\end{tabular}

\section{Discussion of Results}

Research Question 1 sought to establish a relationship between P\&C hands-on proficiency and a deeper understanding of related business concepts. This question was assessed by looking at exam scoring from 10 different class sections, five using a DE delivery and five taught on a FTF basis; in all, 229 students and 840 individual questions comprised the data set. This allowed analysis from four points of view: (1) all data combined; (2) DE delivery; (3) FTF delivery; and (4) individual classes. The preliminary data analysis determined data were normally distributed for all data sets, with mean scores in the middle $70 \%$ range, indicating fair assessment of abilities. In all cases, a statistically significant, moderate positive correlation was determined between the SAP software competencies gained and the absorbed conceptual knowledge relating to the SAP software transactions. Specific correlation coefficients are available in Table 8, and the correlations at the individual course level show a border line strong correlation.

Q2 sought to determine if the pedagogy was equally effective for DE and FTF students. This was evaluated by a means assessments using ANOVA to determine if a statistical difference existed between DE and FTF students on exam questions scores. The SAP proficiency scores were evaluated separately from the business process final exam questions. This allowed a determination for both the SAP hands-on pedagogy and the conceptual business process knowledge gained. In both cases, the results demonstrated there was no statistical difference in mean scores between the two course delivery methods.

The Q2 results also bolstered the Q1 analysis. The purpose of Q2 was to establish the data validity by comparing the mean SAP proficiency scores between the FTF and DE students. Given there was no statistical difference in SAP proficiency between the delivery methods, the interpretation is really twofold. First, the statistical significance of the results was not biased by pre-existing software knowledge. Second, and somewhat tangential to the research, was that the pedagogy was equally effective irrespective of the delivery method and student background. 


\section{Practical Implications}

There is a concern with point-and-click assignments that students are prone to "race to the finish" and focus on the rapid completion of the step-by-step instructions rather than using the effort to gain understanding of what is happening. As previously mentioned, an important pedagogical aspect presented are the discussion question sets specifically linked to P\&C instructional steps. Incorporating discussion questions to complement the $\mathrm{P} \& \mathrm{C}$ steps cannot be separated from the conclusions of the data analysis. While there is a positive, statistically significant correlation, the use of the question sets in combination to the $\mathrm{P} \& \mathrm{C}$ work must be considered a single variable.

These question sets were formally introduced in fall 2014, replacing ad hoc questions introduced during lectures. The question sets reference specific SAP transactions executed, and ask students to explain the context and purpose of the action. These questions serve two purposes, they: (1) slow down the students from the "race to complete" effect; and (2) provide students with a reason to look to the meaning of their actions. A review of Table 8 reveals a subtle shift in the correlation coefficients after that change was introduced.

Further, the discussion questions must be answered during the $\mathrm{P} \& \mathrm{C}$ steps, with student progress paused for consideration at each new question. The intent is for progressive understanding, not a summary review. To maintain the equality of efficacy between the two delivery methods, the question sets are part of the class lecture for FTF sections and used within required asynchronous discussion boards for DE.

From a course administration standpoint, as shown in Table 2, four independent SAP modules may be implemented and still maintain an efficacy of instruction within a 15 -week semester. The results from Q2 may also be interpreted that class time does not need to be devoted to P\&C exercises being instructor led. FTF students completing the SAP work on their own showed no statistical difference to the DE sections. This is an important benefit as P\&C work in a FTF class tends to slow the class down to the pace of the slowest student.

\section{Start-Up and Participation in Academic Alliances}

The data demonstrate the benefits and effectiveness of utilizing an academic alliance with related curriculum content. However, prior to embarking into an academic alliance, a university must consider the capability maturity model shown in Figure 8, as developed by Corbitt and Mensching (2000). If the target is not to achieve Level 3 (Defined), the investment of energy and time should not be undertaken.

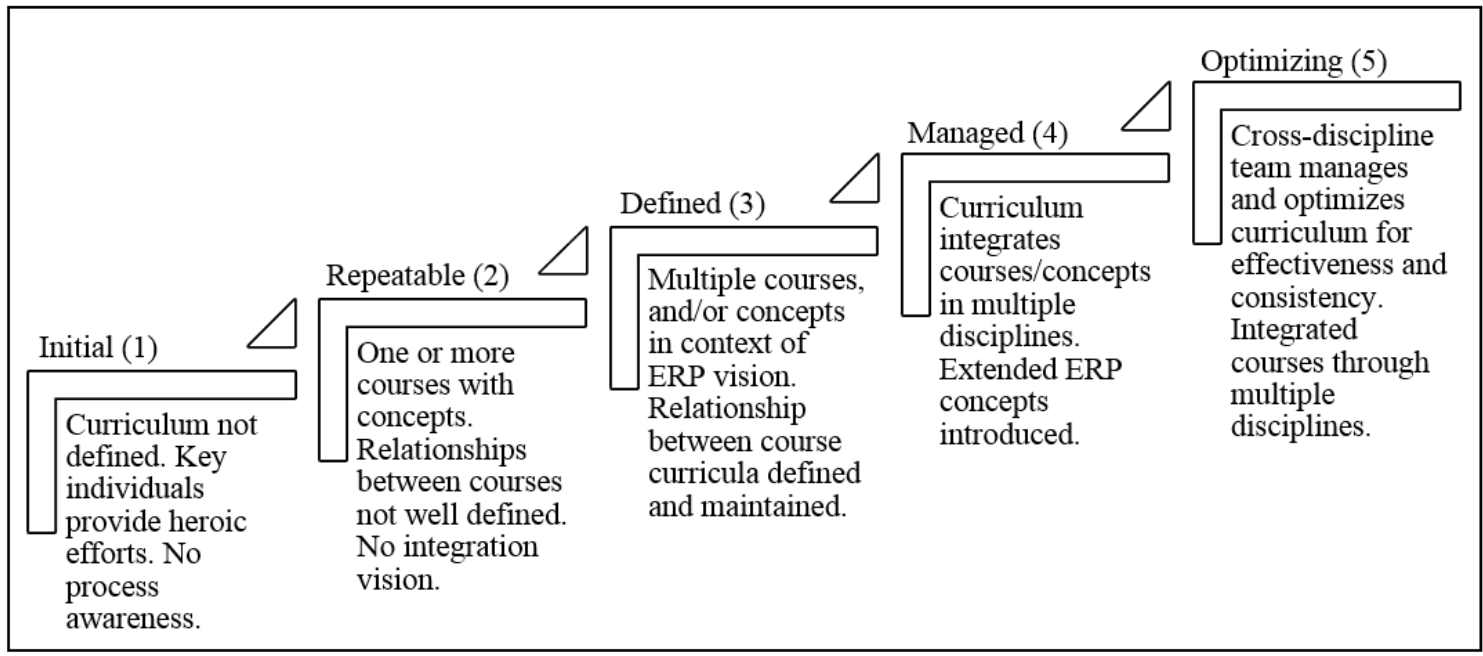

Figure 8. ERP integration maturity (adapted and modified from Antonucci et al. (2004)) 
As least two faculty must be motivated to provide a reasonable chance of success, and preferably more for several reasons. First and foremost is difficulty learning the software, which may take years of trial and error. While university alliances provide web-based and FTF training, most instruction content is point-and-click oriented. Real instructor education comes when students deviate from the prescribed instruction, venturing into unknown territory. Faculty progress up their learning curve and build expertise primarily through forensic analysis of these student problems.

Second, and perhaps more important, is a faculty team collaborating on pedagogy, curriculum integration, and academic productivity. If the vision, funding, and infrastructure can be established, the linchpin to any implementation is a core faculty team. The concern many faculty have with learning enterprise software (or any new IT) tends to fall into the realm of "what's in it for me?" Thus, team is the critical concept, as evidenced by Level 1 on the Capability Maturity Model which points to heroic efforts of single faculty as an unsustainable path.

Finally, while adoption of commercial software provides an avenue for experiential learning, it may also be considered skills-based training. Pedagogy and content inclusion should consider industry applications from the degree discipline, industry advisory boards, and recruiting companies to maximize faculty and student benefits.

Fedorowicz et al. (2004) proposed a model for successful integration of ERP across a curriculum, addressing curriculum, training and support, and student and faculty issues. Corbitt et al. (2000) also delineated challenges to implementation of an academic alliance using an ERP curriculum. Table 11 is a summary of these works, updated based on implementation experience of the authors.

Table 11. Academic alliance implementation: Resources and requirements

\begin{tabular}{|l|l|}
\hline \multicolumn{1}{|c|}{ Resource } & \multicolumn{1}{c|}{ Requirements } \\
\hline Leadership & Departmental vision and desire; faculty curriculum integration \\
\hline Funding & Hosting center fees, training, conferences, curriculum development \\
\hline Infrastructure & Software access, student accounts, virtual networks, labs, student monitors \\
\hline Faculty & Desire, experience, training, learning curve, curriculum coordination, retention \\
\hline Pedagogy & Complimentary text books, exercises, case studies, simulations, innovation \\
\hline Industry & Recruiting, student placement, curriculum direction \\
\hline
\end{tabular}

\section{Conclusions}

There is a growing body of research showing the benefits of universities using an active learning, hands-on approach to IT application skills utilizing commercial software. ERP systems are growing in popularity as enterprise systems are considered an "essential IT infrastructure" by many business organizations (Hawking \& McCarthy, 2004). Recent research also advocates for the use of IT such as ERP to teach business process integration, taking the skills level IT education to the next step (Huynh \& Chu, 2011). Drake (2015) posits that since the 18-22 year-old student demographic has grown up with computers, they tend to "struggle to identify" the purpose of any particular application or information technology. It is incumbent upon the instructor to create a sense of meaningful purpose for the IT being taught.

The current body of knowledge is supported primarily through subjective pre-and-post survey research of students, providing anecdotal evidence that hands-on software training is beneficial. As an example, Rienzo and Han (2011) concluded from student self-assessments that there is a "positive relationship" between students' comprehension of business processes and hands-on experience with ERP software. Hepner and Dickinson (2013) stated that broad educational goals of business operations may be best served by focusing upon use-related skills such as the SAP transactions presented herein. 
This study is a significant step in addressing the gap described by Rienzo and Han (2011) and by Hepner and Dickson (2013) in which they found a lack of quantitative evidence to measure the acquisition of conceptual process knowledge. This research extended their work through quantifiable data collected over two-and-one-half years and 10 separate course sections of an introductory ERP class. The results established the efficacy of point-and-click instructions, supported through contextual discussion questions, as a way to integrate active learning with the Kolb learning cycle. The data analysis demonstrated a statistically significant positive association between SAP transaction skills training and conceptual business process learning. The research also demonstrated that there was no statistically significant difference in applying the described SAP UA supported pedagogy via FTF or distance delivery.

While correlation is not causation, these results quantitatively establish the benefits of using P\&C work for developing IT skills while providing a measure of conceptual learning needed for the application of the skills. Academic alliances have grown to help overcome the financial and infrastructure barriers to the universities that recognize the value of adding hands-on IT curriculum content. For more information about SAP University Alliance program and how to join it, readers are encouraged to visit http://go.sap.com/training-certification/university-alliances.html.

\section{References}

Althouse, N. R., \& Hedges, P. L. (2015). Plan before you play: An activity for teaching the managerial process. Decision Sciences Journal of Innovative Education, 13(4), 515-528.

Antonucci, Y. L., Corbitt, G., Stewart, G., \& Harris, A. L. (2004). Enterprise systems education: Where are we? Where are we going? Journal of Information Systems Education, 15(3), 227-234.

Armstrong, P. (2016). Bloom's taxonomy. Retrieved from https://cft.vanderbilt.edu/guides-subpages/blooms-taxonomy/

Bailey, C. J., \& Card, K. A. (2009). Effective pedagogical practices for online teaching: Perception of experienced instructors. The Internet and Higher Education, 12(3), 152-155.

Botelho, W. T., Marietto, M. d. G. B., Ferreira, J. C. d. M., \& Pimentel, E. P. (2015). Kolb's experiential learning theory and Belhot's learning cycle guiding the use of computer simulation in engineering education: A pedagogical proposal to shift toward an experiential pedagogy. Computer Applications in Engineering Education, 24(1), 79-88.

Cannon, D. M., Klein, H. A., Koste, L. L., \& Magal, S. R. (2004). Curriculum integration using enterprise resource planning: An integrative case approach. Journal of Education for Business, 80(2), 93-101.

Carver, R. (2010). Practical data analysis with JMP. Cary, NC: SAS Institute.

Corbitt, G., \& Mensching, J. (2000). Integrating SAP R/3 into a college of business curriculum: Lessons learned. Information Technology and Management, 1(4), 247-258.

Dhillon, G. (2005). Gaining benefits from IS/IT implementation: Interpretations from case studies. International Journal of Information Management, 25(6), 502-515.

Drake, J. R. (2012). A critical analysis of active learning and an alternative pedagogical framework for introductory information systems courses. Journal of Information Technology Education: Innovations in Practice, 11, 39-52. Retrieved from http://www.informingscience.org/Publications/1546

Fedorowicz, J., Gelinas, U. J., Jr, Usoff, C., \& Hachey, G. (2004). Twelve tips for successfully integrating enterprise systems across the curriculum. Journal of Information Systems Education, 15(3), 235-244.

Felder, R. M., \& Brent, R. (2005). Understanding student differences. Journal of Engineering Education, 94(1), 57-72.

Hawking, P., \& McCarthy, B. (2004). Integrating e-learning content into enterprise resource planning curriculum. Issues in Informing Science \& Information Technology, 1, 23. 
Hepner, M., \& Dickson, W. (2013). The value of ERP curriculum integration: Perspectives from the research. Journal of Information Systems Education, 24(4), 309-326.

Huynh, M. Q., \& Chu, H. W. (2011). Open-source ERP: Is it ripe for use in teaching supply chain management? Journal of Information Technology Education: Innovations in Practice, 10, 181-194. Retrieved from http://www.informingscience.org/Publications/1508

Kolb, D. A. (1984). Experiential learning. Englewood Cliffs, NJ: Prentice-Hall.

Ma, K., Teng, H., Du, L., \& Zhang, K. (2014). Project-driven learning-by-doing method for teaching software engineering using virtualization technology. International Journal of Emerging Technologies in Learning, 9, 26-31.

Microsoft. (2015). Microsoft dynamics academic alliance CRM \& ERP. Retrieved from https://www.microsoft.com/en-us/dynamics/academic.aspx

Nepal, B. P., \& Kumar, P. (2015). Supply chain management: Is it a must course for manufacturing engineering technology? 122nd ASEE Annual Conference \& Exposition, Seattle, WA.

Rienzo, T., \& Han, B. (2011). Does ERP Hands-On experience help students learning business process concepts? Decision Sciences Journal of Innovative Education, 9(2), 177-207. doi:10.1111/j.15404609.2011.00300.x

SAP University Alliances. (2015). Retrieved from http://go.sap.com/training-certification/universityalliances.html

Stanton, N. A., Porter, L. J., \& Stroud, R. (2001). Bored with point and click? Theoretical perspectives on designing learning environments. Innovations in Education and Teaching International, 38(2), 175182.

Su, Y., \& Yang, C. (2010). Why are enterprise resource planning systems indispensable to supply chain management? European Journal of Operational Research, 203(1), 81-94.

Untener, J. A., Mott, R. L., \& Jones, B. (2015). Preparing students for industry by integrating commercial software into coursework. 122nd ASEE Annual Conference \& Exposition, Seattle, WA. 


\section{Appendix}

\section{Research Question 1}

Q1.2: Correlation of Data Pooled by Delivery Method = DE

Distribution Section = DE; Ave SAP

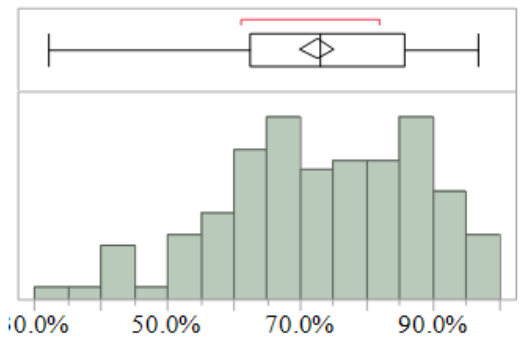

\begin{tabular}{|l|r|}
\hline Mean & 0.7266 \\
\hline Std Dev & 0.1481 \\
\hline $\mathrm{N}$ & 124 \\
\hline Skewness & -0.4163 \\
\hline Kurtosis & -0.4333 \\
\hline Median & 0.73 \\
\hline
\end{tabular}

Distribution Section $=$ DE; BP Final

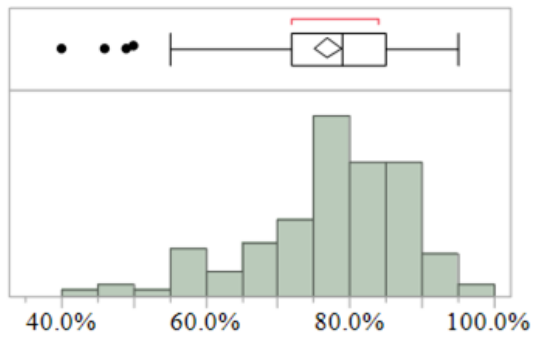

\begin{tabular}{|l|r|}
\hline Mean & 0.7706 \\
\hline Std Dev & 0.1088 \\
\hline $\mathrm{N}$ & 124 \\
\hline Skewness & -0.9537 \\
\hline Kurtosis & 0.8960 \\
\hline Median & 0.79 \\
\hline
\end{tabular}

Q1.3: Correlation of Data Pooled by Delivery Method $=$ FTF Distribution Section = FTF; Ave SAP

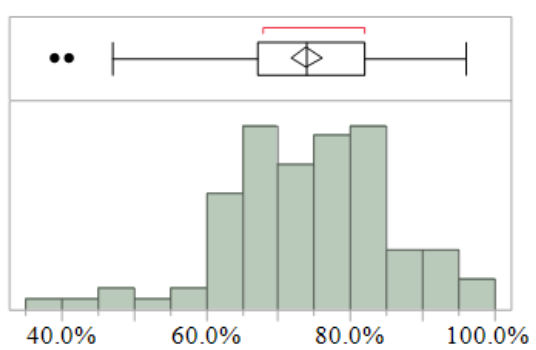

\begin{tabular}{|l|r|}
\hline Mean & 0.74 \\
\hline Std Dev & 0.1123 \\
\hline $\mathrm{N}$ & 105 \\
\hline Skewness & -0.5238 \\
\hline Kurtosis & 0.6293 \\
\hline Median & 0.74 \\
\hline
\end{tabular}

Distribution Section $=$ FTF; BP Final

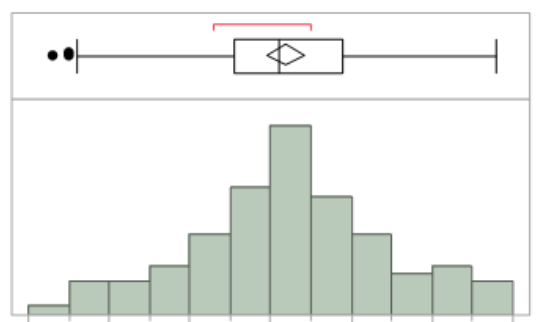

\begin{tabular}{|l|r|}
\hline Mean & 0.7189 \\
\hline Std Dev & 0.1197 \\
\hline $\mathrm{N}$ & 105 \\
\hline Skewness & -0.0416 \\
\hline Kurtosis & -0.0055 \\
\hline Median & 0.71 \\
\hline
\end{tabular}

$0.0 \% 50.0 \% \quad 60.0 \% 70.0 \% \quad 80.0 \% 90.0 \%$ 


\section{Research Question 2}

\section{Normality Assumption Testing for ANOVA}

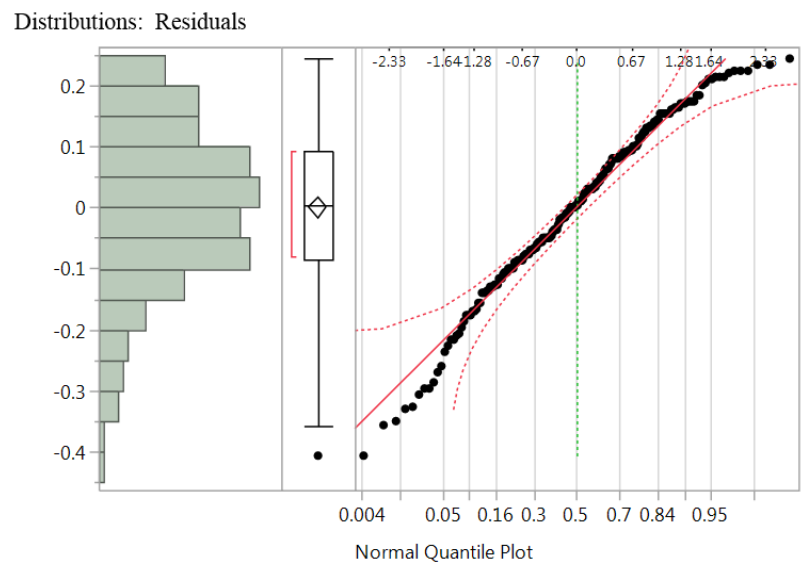

Tests that the Variances are Equal

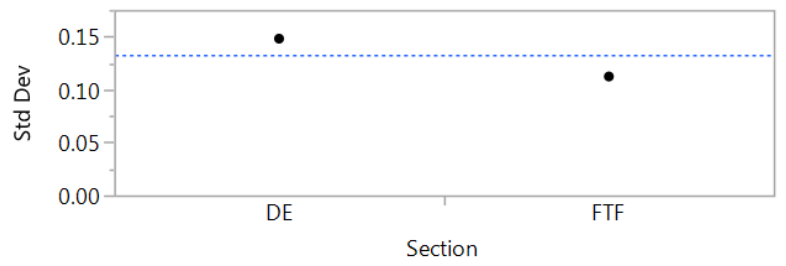

\begin{tabular}{|c|c|c|c|c|}
\hline Level & Count & Std Dev & $\begin{array}{c}\text { MeanAbsDif } \\
\text { to Mean }\end{array}$ & $\begin{array}{c}\text { MeanAbsDif } \\
\text { to Median }\end{array}$ \\
\hline DE & 124 & 0.1481 & 0.1227 & 0.1226 \\
\hline FTF & 105 & 0.1123 & 0.0878 & 0.0878 \\
\hline
\end{tabular}

\begin{tabular}{|c|c|c|c|c|}
\hline Test & F Ratio & DFNum & DFDen & $p$-Value \\
\hline Levene & 11.7865 & 1 & 227 & $0.0007^{*}$ \\
\hline
\end{tabular}

\section{Research Question 2.2 ANOVA detail for FTF delivery}

Oneway Analysis of [Final Exam SAP] by Section

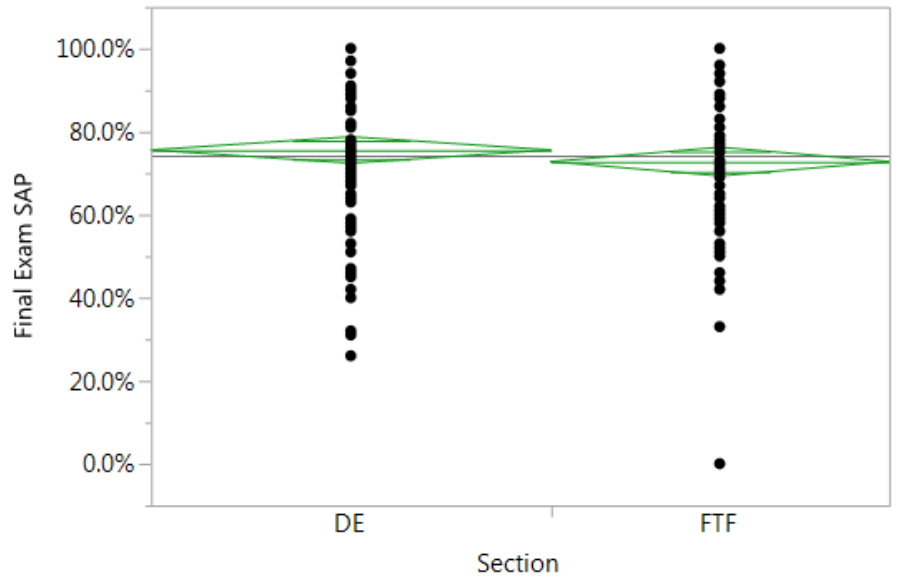




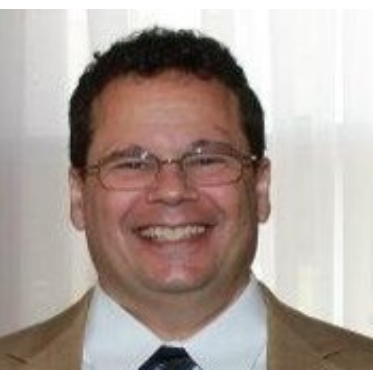

Dr Mark G. Angolia is an Assistant Professor in College of Engineering and Technology at East Carolina University. He holds a PhD in Technology Management from Indiana State University, a Master of Engineering from Rensselaer Polytechnic Institute, and professional certifications of CPIM and CSCP from APICS and a PMP from PMI. After a 20 year career in the automotive supply chain, he has been teaching with ECU's Department of Technology Systems since 2005. His teaching and research interests include supply chain management and enterprise resource systems.

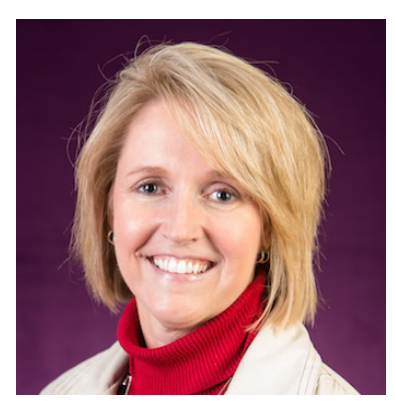

Dr Leslie Pagliari serves as Associate Dean for Academic Affairs in the College of Engineering and Technology and Associate Professor of Technology Systems and. Her research interests center on STEM initiatives, leadership, global supply chain issues, and new technologies in the distribution and logistics sector. She was one of three professors in the United States recognized in an Inbound Logistics Article featuring leading professors in today's supply chain curriculum. She was past president of APICS and past Education Chair for the CSCMP. She completed BRIDGES Academic Leadership for Women hosted by UNC-Chapel Hill. 